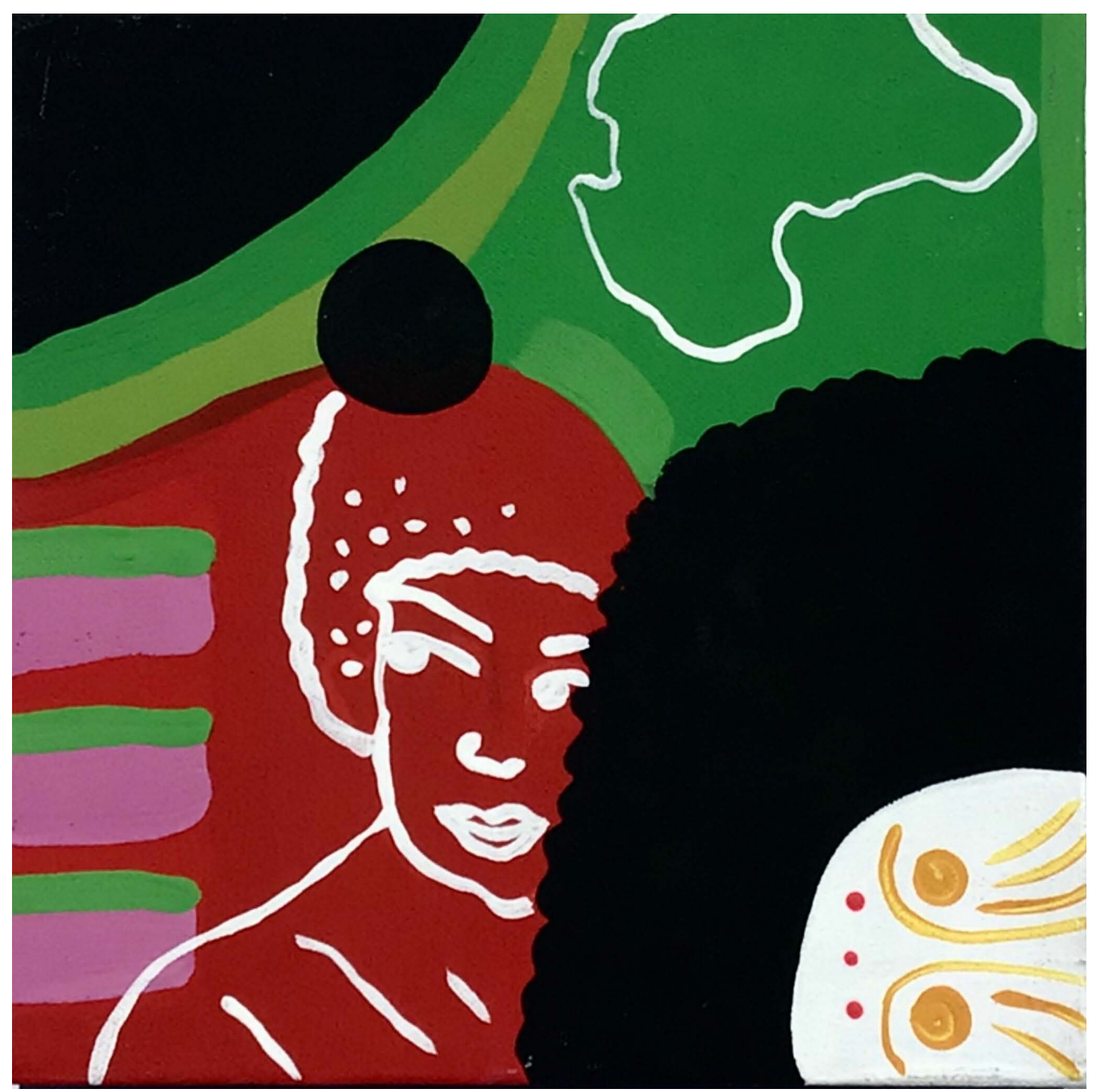

Artista invitado

Fabio Andrés Arboleda Mendoza

Afrikans

De la serie neWeed

Acrílico sobre lienzo

$20 \times 20 \mathrm{~cm}$

2020

Medellín 


\title{
Reforma Rural Integral y construcción de paz para las mujeres en Colombia*
}

\author{
Vanesa Botero Blandón (Colombia)** \\ Ana María Serrano Ávila (Colombia) ${ }^{* * *}$
}

\section{Resumen}

A partir de una perspectiva feminista, este artículo plantea que la propuesta de Reforma Rural Integral (RRI) puede contribuir a mejorar las desigualdades epistémicas entre hombres y mujeres dentro del contexto rural. Se revisó cómo ha avanzado la implementación de esta reforma pactada como parte del Acuerdo de paz entre las Fuerzas Armadas Revolucionarias de Colombia-Ejército del Pueblo (FARC-EP) y el Gobierno colombiano. Para ello se construyó la Matriz IMEG-Paz, en la cual se identificaron las medidas con perspectiva de género incluidas en la RRI y se les dio seguimiento por medio de la triangulación de la información obtenida en una amplia revisión documental. Hasta el momento, preocupan los limitados avances en los tres puntos que la conforman. Estos avances se han centrado hasta el momento en la adecuación institucional y normativa, más que en la materialización en la vida de las mujeres. También preocupa la falta de una estrategia clara que permita hacer el monitoreo a la implementación del Acuerdo final con enfoque de género, especialmente en su condición territorial.

\section{Palabras clave}

Construcción de Paz; Reforma Rural Integral; Feminismo; Enfoque de Género; Colombia.

Fecha de recepción: noviembre de 2020

- Fecha de aprobación: mayo de 2021

\footnotetext{
* Artículo derivado de la investigación realizada en el Grupo Observatorio Público, Tecnológico de Antioquia, Descripción y seguimiento de las medidas que incorporan la perspectiva de género en el acuerdo de paz firmado entre el gobierno colombiano y las FARC en Antioquia. Aprobado en convocatoria interna de CODEI (2018), aprobado en Acto del 18/01/2019, código 206001155.

** Politóloga. Docente investigadora de la Facultad de Ciencias Administrativas y Económicas, Tecnológico de Antioquia. Correo electrónico: vanesa.botero@tdea.edu.co - Orcid: 0000-0003-38593908 - Google Scholar: https://scholar.google.es/citations?hl=es\&user=2pvQrOUAAAAJ

*** Economista. Magíster en Gestión Pública. Grupo Observatorio Público y docente investigadora de la Facultad de Ciencias Administrativas y Económicas, Tecnológico de Antioquia. Correo electrónico: amserrano@tdea.edu.co - Orcid: 0000-0002-4828-6496 - Google Scholar: https://scholar.google.com/ citations?hl=es\&user $=$ nSUHnXUAAAAJ
} 


\title{
Cómo citar este artículo
}

Botero Blandón, Vanesa y Serrano Ávila, Ana María. (2021). Reforma Rural Integral y construcción de paz para las mujeres en Colombia. Estudios Políticos (Universidad de Antioquia), 62, pp. 152-182. https://doi.org/10.17533/udea.espo. n62a07

\section{Comprehensive Rural Reform and Peacebuilding for Women}

\begin{abstract}
From a feminist perspective, this article consider that the Comprehensive Rural Reform (RRI) proposal can contribute to improving epistemic inequalities between men and women within the rural context. It was reviewed how the implementation of this reform agreed as part of the Peace Agreement between the Revolutionary Armed Forces of Colombia-People's Army (FARC-EP) and the Colombian Government has progressed. For this, the IMEG-Peace Matrix was constructed, in which the measures from a gender perspective included in the RRI were identified and followed up by triangulating the information obtained in an extensive documentary review. So far, the limited progress in the three points that make it up is worrying. These advances have focused on institutional and regulatory adaptation, rather than on materialization in the lives of women. There is also concern about the lack of a clear strategy that allows monitoring the implementation of the Final Agreement with a gender perspective, especially in the territories.
\end{abstract}

\section{Keywords}

Peacebuilding; Comprehensive Rural Reform; Feminism; Gender Approach; Colombia. 


\section{Introducción}

La labor de terminar el prologando y complejo conflicto armado colombiano ha sido una tarea igualmente larga y difícil. Los mayores esfuerzos por encontrar una solución negociada a la confrontación armada en el país se han dado a partir de la década de 1980. Entre 1981 y 2016 tuvieron lugar ocho acuerdos humanitarios y de cese al fuego, y nueve acuerdos de paz (Valencia, 2017). El más reciente hito en la búsqueda de paz fue el acuerdo firmado en 2016 entre dos de los principales actores del conflicto interno colombiano: las Fuerzas Armadas Revolucionarias de Colombia-Ejército del Pueblo (FARC-EP) y el Estado colombiano en cabeza del gobierno de Juan Manuel Santos.

Encontrarle solución a un conflicto de más de medio siglo, de múltiples actores, causas y modalidades, no es una tarea sencilla. Posiblemente por ello el Acuerdo final para la terminación del conflicto y la construcción de una paz estable y duradera (Gobierno de Colombia y FARC-EP, 2016) es un documento extenso y comprensivo en el cual confluyen diferentes temas y enfoques conducentes a la implementación de una serie de medidas y reformas institucionales que se plantean como necesarias para solucionar algunas de las causas históricas de la violencia, reversar o reparar, hasta donde sea posible, los efectos del conflicto y construir una paz que perdure en el tiempo.

El primer punto del Acuerdo Final es la Reforma Rural Integral (RRI). EI problema agrario hace parte de la historia del país, y se encuentra en la raíz del conflicto armado. De hecho, la mismas FARC-EP son una guerrilla de origen campesino que desde sus inicios en 1964 reclamaba la importancia de una reforma rural en su Programa Agrario (CNMH, 2014). La conexión entre la cuestión agraria y el conflicto, la reaparición en el presente siglo de la discusión sobre la tierra, especialmente vinculada a los debates en torno al despojo, el desplazamiento y la restitución $(\mathrm{GMH}, 2010)$, y las demás problemáticas asociadas a la ruralidad, como lo son el abandono estatal, la pobreza, la escaza provisión de bienes y servicios públicos, la desigualdad, entre otras, derivó en que el primero de los seis puntos del Acuerdo Final fuera la RRI.

La RRI se desarrolla por medio de tres componentes básicos: a) acceso, restitución, uso y formalización de la tierra —en adelante, Tierras-; b) Programas de Desarrollo con Enfoque Territorial (PDET); y c) Planes 
Nacionales para la Reforma Rural Integral (PNRRI). Asimismo, otra cuestión clave en el Acuerdo final es el enfoque de género. El presente artículo, cuyo objetivo es indagar cómo ha sido hasta el momento la implementación del enfoque de género de la RRI, asume este enfoque desde una perspectiva feminista. Es decir, que el punto de vista del que parte el análisis es que las medidas establecidas deben favorecer la superación del estado de opresión e inequidad en el que se encuentran las mujeres, particularmente, las mujeres rurales.

La perspectiva de género es un estrategia metodológica y epistemológica propuesta desde el pensamiento feminista para visibilizar, comprender y analizar las consecuencias negativas que tiene el sistema político patriarcal en el proyecto de vida de las mujeres $y$, en concordancia, proponer o emprender acciones encaminadas a la superación de las desigualdades generadas por este sistema de relacionamiento sexual y social (Lagarde, 1994). Es importante señalar que una de las consecuencias de las miradas jerárquicas y hegemónicas que tienen las estructuras de poder masculina es la condición subalterna que recae sobre la subjetividad. En el caso concreto de las mujeres campesinas y desde una mirada interseccional, recaen no solo opresiones y desigualdades de sexo genéricas con sus implicaciones materiales, sino que también se presentan marginaciones heredadas de su condición de sujeto colectivo campesino.

En términos generales, el Acuerdo final propone acciones afirmativas encaminadas a la disminución de los sesgos de género en el ámbito rural; no obstante, una cosa es lo acordado y otra su implementación. De ahí que sea indispensable darle seguimiento a uno de los grandes logros en cuanto al tema de paz con perspectiva de género, producto de la acción-reflexión del movimiento social de mujeres y feminista en su expresión más global, que encuentra su génesis en la posguerra y que se materializó en acciones como la aprobación de Resolución 1325 de 2000 y las resoluciones subsecuentes sobre las mujeres, la paz y la seguridad aprobadas por el Concejo de Seguridad de las Naciones Unidas.

La metodología de la investigación, aparte de proponer a la perspectiva de género como marco epistémico y metodológico, se basó en la revisión documental y para alcanzar el propósito del artículo se examinaron el Acuerdo final y su normatividad asociada, el Plan Marco de Implementación (PMI), y el documento con las 4606 iniciativas Plan de Acción para la Transformación 
Regional (PATR) con etiqueta Género y mujer enviado por la Agencia de Renovación del Territorio (ART). También se examinaron los informes de gestión de diversas entidades públicas y los informes de seguimiento realizados por organizaciones como el Instituto Kroc; la Secretaría Técnica del Componente Internacional de Verificación, conformada por el Centro de Investigación y Educación Popular (Cinep) y el Centro de Recursos para el Análisis de Conflictos (Cerac); la Instancia Especial de Mujeres para el Enfoque de Género en la Paz, ONU Mujeres, Humanas Colombia, Sisma Mujer y Red Nacional de Mujeres; además, se complementó la información con artículos académicos y datos suministrados por el Sistema Integrado de Información para el Posconflicto SIIPO 2.0 (SIIPO) y el Observatorio de Tierras Rurales (OTR), y comunicaciones llevadas a cabo con la ART por medio de derechos de petición.

Se utilizó como instrumento para el análisis de la información la Matriz Mujer y Enfoque de Género para la Paz (Matriz IMEG-Paz), la cual fue elaborada por las investigadoras para identificar y darle seguimiento a las medidas a favor de las mujeres. En ella se triangularon las iniciativas identificadas en el Acuerdo final con la información obtenida de la revisión documental; además, está contó con una sección específica para trabajar las iniciativas PATR marcadas por la ART con la etiqueta Género y mujer rural, las cuales se clasificaron de la siguiente manera:

$-0=$ No se identifica enfoque de género o medida a favor de las mujeres. No es clara la razón de su marcación por parte de la ART.

-1 = Solo incorpora lenguaje incluyente.

$-2=$ Se identifica enfoque de género o medida a favor de las mujeres.

En este sentido, los criterios utilizados en la investigación para seleccionar las iniciativas de mujer y enfoque de género, que se corresponden con los utilizados por la Matriz IMEG-Paz en general, fueron:

- Que la iniciativa hiciera explícita mención a medidas a favor de las mujeres, descartando aquellas que se limitaran a utilizar un lenguaje incluyente. Aunque es importante que las iniciativas nombren a las mujeres, por ejemplo, mencionar «campesinos y campesinas», esto por sí solo no las configura como medidas afirmativas, así como su omisión no significaría que son exclusivas para hombres. 
- Que la iniciativa incorpore de forma expresa el enfoque de género, excluyendo las que de manera general indiquen tener enfoque diferencial. Puesto que este enfoque incluye muchos otros grupos poblacionales $y$, de hecho, la mayoría corresponden a enfoque diferencial étnico.

— Que la iniciativa contemple medidas para población LGBTI.

- Que la iniciativa, pese a no cumplir con ninguno de los tres criterios anteriores, aborden problemáticas que social e históricamente han sido asociadas a las mujeres, como lo son el embarazo adolescente, las unidades materno-infantil, la violencia basada en género, los derechos sexuales y reproductivos, la prostitución, entre otros.

La parte expositiva de los resultados de la investigación, que se desarrolla a continuación, está de conformidad con los tres componentes de la RRI; sin embargo, antes es necesario hacer algunas precisiones conceptuales.

\section{Enfoque de género y construcción de paz para las mujeres rurales}

Una de las primeras interpelaciones hechas desde el pensamiento feminista se fundamenta en develar violencias epistémicas producidas por las estructuras de poder patriarcal y sus consecuencias en la materialidad y en la subjetividad del proyecto vital de las mujeres. No obstante, las mujeres hemos sido capaces de nombrar y colectivizar nuestras opresiones en clave de buscar soluciones a las problemáticas que generan dichas opresiones, pero, sobre todo, con un sentido de preservación de la existencia y de la vida misma. La construcción epistemológica feminista que aborda problemas ontológicos es un ejemplo de cómo se articula la reflexión y la acción de forma colectiva producto de una experiencia histórica acumulada, dando paso a una politicidad de la cotidianidad en clave femenina (Segato, 2018, p. 17).

En las últimas tres décadas la comprensión y práctica en torno a la construcción de paz ha ido cambiando. Desde esta perspectiva, uno de los temas abordados y reflexionados durante la cuarta Conferencia Mundial de Mujeres realizada en Beijín en 1995 (UN Women, s. f.) fueron las problemáticas de las mujeres rurales en torno a la violencia, la pobreza y el acceso al uso y tenencia de la tierra. Estas problemáticas han suscitado 
profundas reflexiones y análisis en el contexto colombiano, entendiendo que a consecuencia del conflicto armado en el país se presentan fenómenos como el desplazamiento y el despojo, y que juntos traen consigo el deterioro de las condiciones de vida de las mujeres campesinas.

Así las cosas, desde el decenio de 1990 se ha apostado por procesos de paz más locales, con extendida participación de otros actores diferentes a los armados en los cuales se involucre activamente a la sociedad civil y con una agenda amplia sobre los temas que engloba la paz, vista no ya desde el minimalismo de la ausencia de conflicto, sino como un proceso multidimensional a largo plazo (Rettberg, 2013).

Un concepto global que abarca, produce y sostiene toda la serie de procesos, planteamientos y etapas necesarias para transformar los conflictos en relaciones más pacíficas y sostenibles. El término incluye, por tanto, una amplia gama de actividades y funciones que preceden y siguen a los acuerdos formales de paz. Metafóricamente, la paz no se ve solamente como una fase en el tiempo o una condición; es un proceso social dinámico y como tal requiere un proceso de construcción (Lederach, 2007, p. 54).

[158] En este sentido, la construcción de paz es un proceso que exige su apropiación por parte de la sociedad y la implementación de una serie de acciones que van más allá de las negociaciones, las cuales empiezan con anterioridad y se extienden en el tiempo en la búsqueda de escenarios más pacíficos.

El género, como organizador social, influye en la forma como hombres y mujeres experimentan el mundo. La categoría analítica de género pretende desesencializar y desbiologizar la noción del sujeto mujer, dando cuenta de que «las representaciones dominantes y hegemónicas, organizan el mundo de la sexualidad, de los afectos, de los roles sociales y de la personalidad» (Segato, 2018, p. 28). El conflicto armado, la construcción de paz, y el desarrollo social no se escapan a este horizonte político. Por lo tanto, un proceso de paz que realmente le apueste a generar una transformación democrática debe contener un sentido diferenciador en cuanto a las afectaciones que tiene la violencia directa producto de la guerra en los sujetos y, desde este punto de vista, incluir los sentires y reclamos de mujeres y hombres de manera diferencial. Así fue entendido en las negociaciones de paz de La Habana, razón por la que se incorporó de manera transversal 
el enfoque de género. En el primer punto del Acuerdo final se concibe el enfoque de género como:

[El] Reconocimiento de las mujeres como ciudadanas autónomas, sujetos de derechos que, independientemente de su estado civil, relación familiar o comunitaria, tienen acceso en condiciones de igualdad con respecto a los hombres a la propiedad de la tierra y proyectos productivos, opciones de financiamiento, infraestructura, servicios técnicos y formación, entre otros; atendiendo las condiciones sociales e institucionales que han impedido a las mujeres acceder a activos productivos y bienes públicos y sociales (Gobierno de Colombia y FARC-EP, 2016, p. 12).

Aunque muchas veces en el Acuerdo final, más que entender el enfoque de género como una categoría analítica, parece equipársele al término mujer, lo cierto es que, al hacer uso de este enfoque, que es relacional, sí se evidencia la situación de subalternidad social de las mujeres respecto a los hombres.

En articulación con lo mencionado anteriormente, las políticas agrarias del país por mucho tiempo fueron pensadas no desde enfoques diferenciales y de género, sino familistas y patriarcales, en las que se daba preponderancia a los hombres como jefes de hogar, desconociendo los aportes de las mujeres rurales; esto, aunado a las distintas leyes, normas consuetudinarias, costumbres y falta de registros y datos sobre la tierra desagregados por sexo han contribuido al escaso acceso formal a la propiedad por parte de las mujeres campesinas (UNFPA y ONU-Hábitat, s. f.; Meertens, 2016b). Dentro del contexto colombiano de conflicto armado y desplazamiento, esto plantea retos adicionales para reparar y dar garantías de no repetición de la violencia sexual, simbólica, física, económica y patrimonial que han sufrido las mujeres campesinas colombinas, especialmente en las zonas priorizadas por los PDET.

La implementación de los programas acordados en la Mesa de La Habana tendrá que enfrentarse, a nivel local, a las fuerzas que se oponen a la democratización y a la justicia de género, presentes no solo en las prácticas tradicionales de la sociedad campesina, sino en las prácticas de poder de viejas y nuevas fuerzas acumuladoras de tierras (Merteens, 2016b, p. 20).

En consecuencia, se hace indispensable la adopción de medidas que contribuyan a superar las inequidades y discriminaciones que sufren las 
mujeres, ${ }^{1}$ y por extensión, la necesidad de continuar haciendo investigación feminista sobre el tema, entendida como la que busca «mejorar la condición de las mujeres» (Bartra, 2010), a fin de aportar desde la academia y de la sociedad al anhelo de construir paz territorial para las mujeres, en general, y para las mujeres rurales, en particular. Resulta claro que dimensiones como la feminización de la pobreza, el problema del acceso, uso y tenencia de la tierra, la casi exclusividad en la dedicación de las mujeres a las labores del cuidado y la falta de acceso a una educación que les permita una mayor inserción y participación en espacios deliberativos están directamente relacionadas con la ausencia de oportunidades y de acceso a derechos de las mujeres rurales. En ese sentido, existe una deuda social y epistémica de sacar de la marginación y subestimación a las mujeres, su identidad y las relaciones de género en contextos rurales (Ortega, 2015).

Una de las estrategias para superar la discriminación y desigualdad estructural que han venido incorporando los Estados desde mediados del siglo xx son las denominadas acciones afirmativas o medidas afirmativas, que no limitan la igualdad a su dimensión formal, sino que se encaminan a la búsqueda de una igualdad sustancial, «en virtud de la cual deben ser removidos, o por lo menos reducidos, "los obstáculos de orden económico y social que [...] impiden el pleno desarrollo de la persona humana"» (Ferrajoli, 2019, p. 174). En tal sentido, son cada vez más las acciones afirmativas que se adoptan como recurso, de carácter temporal, para combatir las desventajas históricas que recaen sobre las mujeres a consecuencia de la discriminación por género (Pérez, 2010). Sobre este particular, el Acuerdo final establece que: «Para garantizar una igualdad efectiva se requiere adelantar medidas afirmativas que respondan a los impactos desproporcionados que ha tenido el conflicto armado en las mujeres, en particular la violencia sexual»; agrega que estas medidas diferenciadas les deben garantizar a las mujeres participación y representación equitativa, y acceso igualitario a todos los programas; además, «el enfoque de género deberá ser entendido y aplicado de manera transversal en la implementación de la totalidad del Acuerdo» (Gobierno de Colombia y FARC-EP, 2016, pp. 193-194).

\footnotetext{
${ }^{1}$ Aunque el enfoque diferencial y de género también implica el reconocimiento de las experiencias propias de las disidencias sexuales, este aspecto es menos desarrollado en el Acuerdo final. A pesar de que el presente trabajo se centra en las medidas con enfoque de género a favor de las mujeres, se toman en cuenta algunas de estas iniciativas plasmadas en los PDET, en el entendido de que las identidades y orientaciones no normativas hacen parte integral de las vivencias interseccionales de las mujeres en los territorios.
} 
Con base en lo anterior, se puede inferir que el Acuerdo final establece dos disposiciones distintas, pero complementarias: la transversalización del enfoque de género en la implementación general y la adopción de medidas afirmativas particulares. En cuanto a la cantidad de medidas específicas que al respecto contiene el Acuerdo, la cifra cambia dependiendo de la fuente, como se puede observar en la tabla 1. Estas discrepancias obedecen principalmente a los criterios utilizados por los y las autoras de los diversos informes al momento de ubicar, clasificar, filtrar y definir las medidas a las cuales darle seguimiento. Por su parte, el PMI elaborado por el Gobierno para orientar la implementación del Acuerdo - y discutido en la Comisión de Seguimiento, Impulso y Verificación a la Implementación (CSIVI) que realizó una serie de salvedades sobre el documento-, contiene 51 indicadores para la transversalización del enfoque de género.

Tabla 1. Medidas con enfoque de género en el Acuerdo final, según los principales informes publicados.

\begin{tabular}{|l|l|l|l|}
\hline \multicolumn{1}{|c|}{ Institución que produce el informe } & \multirow{2}{*}{ Año } & \multicolumn{2}{c|}{ Cantidad } \\
\cline { 3 - 4 } & & \multicolumn{1}{c|}{ Acuerdo } & \multicolumn{1}{c|}{ RRI } \\
\hline ONU Mujeres & 2017 & 100 & 27 \\
\hline $\begin{array}{l}\text { Humanas Colombia, Sisma Mujer, Red Nacional de } \\
\text { Mujeres }\end{array}$ & 2017 & 122 & 25 \\
\hline $\begin{array}{l}\text { Grupo Género en la Paz (GPAZ). Grupo integrado por } \\
\text { distintas organizaciones. }\end{array}$ & 2019 & 122 & 25 \\
\hline Instancia Especial de Mujeres & 2019 & $100^{*}$ & 27 \\
\hline Instituto Kroc & 2020 & 130 & 39 \\
\hline Gobierno Nacional (PMI) & 2018 & $51 * *$ & $19^{* *}$ \\
\hline $\begin{array}{l}* \\
* *\end{array}$ & & & \\
\hline
\end{tabular}

Fuente: elaboración propia a partir de ONU Mujeres (2018); Instituto Kroc (2020); Humanas Colombia, Sisma Mujer, Red Nacional de Mujeres (2017); Instancia Especial de Mujeres para el Enfoque de Género en la Paz (2019); GPAZ (2019); DNP (s. f.).

Análogamente, la cantidad de medidas identificadas en el primer punto del Acuerdo también difiere de un informe a otro (véase tabla 1). La presente investigación distinguió 26 medidas por medio de la matriz IMEG-Paz, las cuales son detalladas a continuación y divididas en los tres grandes subtemas de la RRI: Tierras, PDET y PNRRI. La información se complementará con 
los principales avances en su implementación en el ámbito nacional hasta octubre de 2020.

\section{Acceso, restitución, uso y formalización de la tierra (Tierras)}

La Ley de Reforma Agraria 160 de 1994, así como la Ley de Víctimas y Restitución de Tierras 1448 de 2011, empiezan a abandonar las políticas familistas y a reconocer los aportes y necesidades de las mujeres rurales; sin embargo, las realidades sociales y prácticas excluyentes naturalizadas por la familia, la comunidad y los funcionarios del Estado (Meertens, 2016a) han conllevado a que la situación de las mujeres en relación con la tierra continúe siendo desventajosa (véase gráfica 1).

Gráfica 1. Mujeres productoras. Unidades de Producción Agrícola (UPA) de personas naturales en el área rural dispersa según el sexo.

Número total

Distribución porcentual

\begin{tabular}{|c|c|c|c|c|c|}
\hline $\begin{array}{l}\text { UPA de personas naturales del área rural } \\
\text { dispersa }\end{array}$ & 2370099 & $21 \%$ & $50 \%$ & $10 \%$ & $19 \%$ \\
\hline \multirow{2}{*}{$\begin{array}{l}\text { UPA de personas naturales del área rural } \\
\text { dispersa de menos de } 5 \text { ha }\end{array}$} & \multirow[b]{2}{*}{1669287} & & & & \\
\hline & & $23 \%$ & $47 \%$ & $10 \%$ & $20 \%$ \\
\hline \multirow{2}{*}{$\begin{array}{l}\text { UPA de personas naturales que declaran } \\
\text { tener maquinaria }\end{array}$} & \multirow[b]{2}{*}{338576} & & & & \\
\hline & & $15 \%$ & $65 \%$ & & $20 \%$ \\
\hline \multirow{2}{*}{$\begin{array}{l}\text { UPA de personas naturales que recibieron } \\
\text { asistencia técnica durante } 2013\end{array}$} & \multirow[b]{2}{*}{341630} & & & & \\
\hline & & $19 \%$ & $63 \%$ & & $17 \%$ \\
\hline \multirow{2}{*}{$\begin{array}{l}\text { UPA de personas naturales que } \\
\text { solicitaron crédito en } 2013\end{array}$} & \multirow[t]{2}{*}{223721} & $19 \%$ & $61 \%$ & & $20 \%$ \\
\hline & & & & & \\
\hline
\end{tabular}

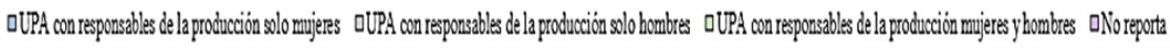

Fuente: elaboración propia a partir de DANE (2016).

Dicha situación ha sido empeorada por el conflicto armado. En el Auto 092 de 2008, en referencia a las mujeres desplazadas, la Corte Constitucional manifiesta que:

Antes del desplazamiento eran propietarias de tierras. Sin embargo, es claro que las mujeres del país históricamente acceden a la propiedad de la tierra y de bienes inmuebles a través de sus compañeros de 
sexo masculino. Como consecuencia de este rasgo estructural, las mujeres enfrentan diversos obstáculos para acreditar la propiedad de la tierra, para conocer sus derechos reales o la extensión de su patrimonio, para contar con los títulos necesarios o con las pruebas de posesión requeridas, incluso para acreditar la relación de pareja con su proveedor, etc. (III.1.8.).

Teniendo en cuenta este escenario, el subtema de tierras en el Acuerdo desarrolla diversas medidas que tienen como objetivo beneficiar a las campesinas, en la Matriz IMEG-Paz se identificaron nueve exactamente (véase cuadro 1), aunque hay algunos avances en su implementación todavía no son significativos. Esto preocupa, puesto que del acceso de las mujeres a tierras depende también la implementación de otras medidas como el desarrollo de proyectos productivos agropecuarios o el acceso a líneas de crédito especiales.

Cuadro 1. Medidas mujeres rurales y enfoque de género: Tierras.

\begin{tabular}{|c|c|}
\hline Resumen medida & Principales avances en la implementación \\
\hline Fondo de Tierras: priorización & $\begin{array}{l}\text { - Tierra ingresada al Fondo: } 1381633 \text { ha. } \\
\text { - Priorización en el Registro de Sujetos de Ordenamiento } \\
\text { (RESO) para acceso y formalización (Decreto Ley } 902 \text { de } \\
\text { 2017). } \\
\text { - Baldíos adjudicados - no necesariamente a través del } \\
\text { Fondo- a mujeres: } 19729 \text {, que representan un área de } \\
353329 \text { ha (30\% del total). } \\
\text { - } 1471,28 \text { ha entregadas a } 825 \text { mujeres a través del } \\
\text { Fondo. }\end{array}$ \\
\hline $\begin{array}{l}\text { Plan de formalización: facilitar } \\
\text { acceso }\end{array}$ & $\begin{array}{l}\text { - Todavía no hay Plan de Formalización Masiva. } \\
\text { - } 358 \text { 405,06 ha formalizadas y adjudicadas -con } \\
\text { normatividad previa-a } 22945 \text { mujeres. }\end{array}$ \\
\hline $\begin{array}{l}\text { Subsidio integral para compra } \\
\text { de tierras: priorización }\end{array}$ & $\begin{array}{l}\text { - } 452 \text { familias en cabeza de mujeres se han beneficiado } \\
\text { de los subsidios (50,1\% del total). }\end{array}$ \\
\hline $\begin{array}{l}\text { Línea de crédito especial } \\
\text { para compra de tierras: } \\
\text { priorización }\end{array}$ & $\begin{array}{l}\text { - Creación de la Línea Especial de Crédito (LEC) con } \\
\text { medidas para las mujeres (Resolución } 4 \text { de } 2019 \text { de la } \\
\text { Comisión Nacional de Crédito Agropecuario [CNCA]). }\end{array}$ \\
\hline $\begin{array}{l}\text { Nueva Jurisdicción agraria: } \\
\text { asesoría legal y formación } \\
\text { especial* }\end{array}$ & \multirow{2}{*}{$\begin{array}{l}\text { - Proyecto de Ley } 134 / 2020 C \text {, «Por la cual se crea una } \\
\text { especialidad judicial rural y agraria», y que contemplaba } \\
\text { medidas especiales para las mujeres. Archivado por falta } \\
\text { de agendamiento. }\end{array}$} \\
\hline $\begin{array}{l}\text { Nueva jurisdicción: } \\
\text { protección de los derechos } \\
\text { sobre la tierra* }\end{array}$ & \\
\hline
\end{tabular}


Cuadro 1. (Continuación).

\begin{tabular}{|l|l|}
\hline \multicolumn{1}{|c|}{ Resumen medida } & \multicolumn{1}{c|}{ Principales avances en la implementación } \\
\hline $\begin{array}{l}\text { Mecanismos Alternativos } \\
\text { de Resolución de Conflictos } \\
\text { (MASC) sobre uso y tenencia } \\
\text { de tierra: participación } \\
\text { mujeres y sus organizaciones }\end{array}$ & $\begin{array}{l}\text { - } 45276 \text { mujeres atendidas en las Casas de Justicia con el } \\
\text { Programa de Conciliación en Equidad (60\% del total), } \\
\text { incluidos conflictos agrarios y por tierras. }\end{array}$ \\
\hline $\begin{array}{l}\text { Instancia de alto nivel para } \\
\text { formulación de lineamientos } \\
\text { sobre uso de la tierra: } \\
\text { representación equitativa* }\end{array}$ & $\begin{array}{l}\text { - Creación del Consejo Superior de la Administración de } \\
\text { Ordenamiento del Suelo Rural (Decreto 2367 de 2015). } \\
\text { mujeres. }\end{array}$ \\
\hline $\begin{array}{l}\text { Catastro multipropósito: } \\
\text { información desagregada por } \\
\text { sexo* }\end{array}$ & $\begin{array}{l}\text { CONPES 3958 de 2019, que define la estrategia para } \\
\text { la implementación de la política pública de catastro } \\
\text { multipropósito. }\end{array}$ \\
\hline $\begin{array}{l}* \text { Medidas sin indicador PMI. } \\
\text { Datos del cuadro con fecha de corte de julio de 2021. }\end{array}$ \\
\hline
\end{tabular}

Fuente: elaboración propia a partir de OTR (s. f.); CPEC (2021); Presidencia de la República (2015; 2017); DNP (s. f.); CNCA (Resolución 4 del 8 de mayo de 2019); Ministerio de Justicia y del Derecho (Proyecto de Ley 134 del 20 de julio de 2020).

[164] Al poco avance en la implementación en este subtema —o nulo, como en el caso de la jurisdicción agraria- se le suma la falta de información clara disponible para hacerle seguimiento. Entre las principales dificultades halladas están: i) no siempre se hace la distinción de qué porcentaje de implementación se debe realmente a los mecanismo concertados en el Acuerdo y qué porcentaje a otros anteriores, como en el caso de la adjudicación de tierras; ii) las cifras varían entre instituciones y no siempre se utiliza la misma unidad de medida; iii) la información se encuentra dispersa y en su mayoría no está desagregada por sexo; iv) las fuentes de información como el SIIPO, que debería reunir la información para facilitar el seguimiento, tiene muchos indicadores sin ficha técnica o con datos desactualizados o no desagregados; y v) en el caso del Fondo de Tierras, el indicador se enfoca más en cuánta tierra entra al Fondo y no en cuánta de distribuye. En cuanto a esto último, la Secretaría Técnica advierte que la caracterización del estado de los predios del Fondo de Tierras no está completa, por lo que no es posible verificar cuántas hectáreas están realmente disponibles para su entrega, a lo que se añade la confusión que hay en el indicador entre acceso y formalización de tierra, obstaculizando conocer el avance real de cada una de estas dos acciones que obedecen a objetivos y medidas diferentes (Cinep y Cerac, 2020b). 
La medida referente a la priorización en el acceso a la LEC para compra de tierras es un ejemplo que ilustra lo limitado que es hasta el momento el SIIPO para el análisis de la implementación de lo acordado. Esta medida es de las pocas que no solo cuenta con un indicador asociado en el sistema, sino dos: el primero es «línea de crédito especial para la mujer para la compra de tierra, ajustada», el cual aparece con un avance de 100\% debido a la Resolución 4 de 2019 de la CNCA, independientemente de que las mujeres realmente hayan accedido a esta; sin embargo, el segundo indicador, "porcentaje de mujeres que acceden a líneas de crédito especial para la compra de tierras», sí respondería al acceso. La forma de cálculo del avance en el indicador, según la ficha técnica, es la cantidad de mujeres que acceden a la LEC para compra de tierras sobre el número total de personas por 100, ya que, hasta junio de 2021, 108 personas habían accedido a la LEC y de estas 31 serían mujeres, significa que $28,7 \%$ de los que han accedido a la LEC son mujeres $y$, puesto que la meta del indicador era $27 \%$ - muy tímida-, habría $106 \%$ de avance en la medida para 2021. Ahora bien, que 31 mujeres accedan en medio año a la LEC para compra de tierras en Colombia no parece dar cuenta del elemento transformador para la ruralidad planteado en el espíritu del Acuerdo, y ese es el caso de la mayoría de los indicadores.

Es fundamental, por lo tanto, mejorar los sistemas de información y avanzar en una implementación que realmente facilite el acceso de las mujeres a tierra, sea a través de adjudicación, subsidio, compra, formalización o restitución. Esta última no solo desde su dimensión material, sino también desde lo social y simbólico (Meertens, 2016a).

\section{Programas de Desarrollo con Enfoque Territorial (PDET)}

Los PDET buscan llevar la transformación estructural del campo que plantea la RRI a zonas del país priorizadas por ser los territorios más fuertemente afectados por el conflicto armado, y por sus altos índices de pobreza, debilidad institucional y presencia de economías ilícitas. En total, fueron priorizados 170 municipios agrupados en 16 subregiones. El enfoque territorial de estos programas implica considerar y reconocer las características y necesidades propias de cada lugar (Gobierno de Colombia y FARC-EP, 2016), para lo cual es imprescindible la participación de los habitantes de estos territorios en la formulación, implementación y seguimiento de los distintos planes, pactos y proyectos que conforman los PDET. 
El Acuerdo final advierte la importancia de la participación de las mujeres rurales en la transformación del campo. Es en este sentido que apunta la única medida explícita identificable en cuanto a los PDET (véase cuadro 2). No obstante, pese a ser la única expresa, al ser los PDET la vía de priorización de la RRI, estos deberían dar cuenta, tanto a nivel de disposiciones generales como específicas para las mujeres, de todo los pactado respecto a tierras y PNRRI. Por su parte, el Decreto Ley 893 de 2017, en concordancia con el Acuerdo, estableció que los PDET debían incorporar un enfoque de género para las mujeres rurales.

Cuadro 2. Medidas mujeres rurales y enfoque de género: PDET.

Resumen medida

Participación de las mujeres y sus organizaciones en la construcción de los PDET

\section{Principales avances en la implementación}

Entre agosto de 2017 y febrero de 2019 instituciones públicas y privadas, organizaciones civiles y representantes de la comunidad construyeron, bajo la coordinación de la ART, los PDET de las 16 subregiones priorizadas. Este proceso se desarrolló con una metodología participativa dividida en 3 fases:

i) Veredal: se elaboraron 305 PCTR (161 pactos comunitarios y 144 pactos comunitarios étnicos). Participaron 61126 mujeres (41\% de los participantes).

ii) Municipal: con base en los PCTR se construyeron 176 PMTR. 6340 mujeres participaron $(38 \%)$.

iii) Subregional: se formularon los 16 PATR que anexan a los PMTR. 1584 mujeres participaron (37\% del total).

En todas las fases se concibieron iniciativas específicas para mujeres.

Fuente: elaboración propia a partir de la ART (comunicación personal, radicados 20206300050032 y 20206300050052 , septiembre 23, 2020).

Aunque aproximadamente $41 \%$ de las personas que asistieron al proceso de construcción de los PDET en las distintas fases fueron mujeres y que la ART diseñó diversas estrategias y herramientas para incentivar dicha asistencia, la participación efectiva de las mujeres tuvo una serie de limitaciones y dificultades.

La Secretaría Técnica del Componente Internacional de Verificación indicó en uno de sus informes como principales problemas el lenguaje técnico de los funcionarios, lo que provocó que muchas de las iniciativas de las mujeres fueran modificadas; el limitado conocimiento de las mujeres en 
relación con el funcionamiento del proceso PDET; la insuficiente capacitación de los funcionarios en asuntos de género; la dificultad para plasmar en la etapa subregional las iniciativas con enfoque de género concebidas en la fase veredal; y el entendimiento de la participación de la mujeres por parte de las instituciones más como una cuestión de cuotas y números que como un ejercicio de real acceso a las discusiones en condiciones igualitarias (Cinep y Cerac, 2018).

A esto se le suma las problemáticas propias del contexto: dificultades para desplazarse desde y hacia las zonas rurales; largas jornadas de trabajo de las mujeres, en gran medida, relacionadas con las labores de cuidado; poca formación en temas participación por parte de ellas; y escasa disponibilidad de traductores que posibilitaran una real participación de las mujeres indígenas. Asimismo, hubo un vacío en la estrategia de participación que diseñó la ART en lo que concierne a la población LGBTI (Cinep y Cerac, 2018) —esta última es una constante en toda la implementación del Acuerdo final-.

Incluso con todas sus limitaciones, la construcción de los PDET sigue siendo un importante ejercicio participativo para las mujeres que contribuye a su fortalecimiento como actoras en el desarrollo rural y que deja como resultado que diversas iniciativas encaminadas a superar las desigualdades históricas de las mujeres rurales quedaran pactadas en los PMTR y en los PATR. La metodología para la construcción de estas iniciativas se desarrolló en torno a ocho pilares que se corresponden a diferentes puntos del Acuerdo.

1. Ordenamiento social de la propiedad rural y uso del suelo.

2. Infraestructura y adecuación de tierras.

3. Salud rural.

4. Educación rural y primera infancia.

5. Vivienda, agua potable y saneamiento básico.

6. Reactivación económica y producción agropecuaria.

7. Garantía progresiva del derecho a la alimentación.

8. Reconciliación, convivencia y construcción de paz.

En las 16 subregiones PDET se elaboraron 4606 iniciativas con marcación de mujer rural y género (véase gráfica 2). 
Gráfica 2. Distribución en los pilares de las iniciativas PDET y con marcación de mujer rural y género.

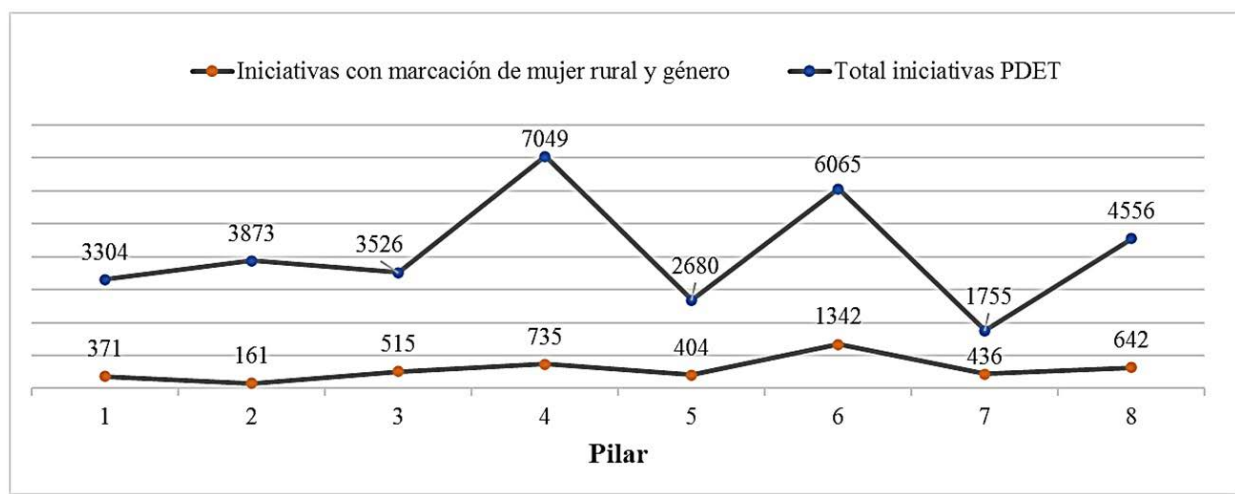

Fuente: elaboración propia a partir de la ART (comunicación personal, radicado 20212300048592, mayo 28, 2021).

Tanto en las medidas generales como en las que tienen marcación mujer rural y género los pilares con mayor cantidad de iniciativas fueron el 4 (educación), el 6 (reactivación económica) y el 8 (construcción de paz). En el caso de las mujeres primaron las iniciativas en torno a lo económico; sin embargo, en la sistematización y clasificación desarrollada por medio de la Matriz IMEG-Paz a estas iniciativas marcadas por la ART solo se identificaron como medidas para mujeres o con enfoque de género 1814 (véase tabla 2).

Tabla 2. Iniciativas con marcación mujer rural y género, desagregadas por subregión.

\begin{tabular}{|l|c|c|c|}
\hline \multirow{2}{*}{ Subregión } & \multicolumn{2}{c|}{$\begin{array}{c}\text { Iniciativas con marcación } \\
\text { mujer rural y género }\end{array}$} & \multirow{2}{*}{ Diferencia } \\
\cline { 2 - 4 } & ART & Matriz IMEG-Paz & \\
\hline Pacífico Medio & 13 & 13 & 0 \\
\hline Bajo Cauca y Nordeste Antioqueño & 169 & 116 & 53 \\
\hline Sierra Nevada-Perijá-Zona Bananera & 182 & 78 & 104 \\
\hline Urabá Antioqueño & 105 & 68 & 37 \\
\hline Macarena-Guaviare & 324 & 96 & 228 \\
\hline Sur de Córdoba & 138 & 81 & 57 \\
\hline Sur de Bolívar & 118 & 41 & 77 \\
\hline Montes de María & 538 & 244 & 294 \\
\hline
\end{tabular}


Tabla 2. (Continuación).

\begin{tabular}{|l|c|c|c|}
\hline \multirow{2}{*}{ Subregión } & \multicolumn{2}{c|}{$\begin{array}{c}\text { Iniciativas con marcación } \\
\text { mujer rural y género }\end{array}$} & \multirow{2}{*}{ Diferencia } \\
\cline { 2 - 4 } & ART & Matriz IMEG-Paz & \\
\hline Cuenca del Caguán y Piedemonte Caqueteño & 514 & 235 & 279 \\
\hline Arauca & 166 & 121 & 45 \\
\hline Catatumbo & 278 & 53 & 225 \\
\hline Chocó & 195 & 63 & 132 \\
\hline Sur del Tolima & 203 & 78 & 125 \\
\hline Alto Patía y Norte del Cauca & 1179 & 285 & 894 \\
\hline Putumayo & 305 & 159 & 146 \\
\hline Pacífico y Frontera Nariñense & 179 & 83 & 96 \\
\hline Total & 4606 & 1814 & 2792 \\
\hline
\end{tabular}

Fuente: elaboración propia a partir de la Matriz IMEG-Paz y la ART (comunicación personal, radicado 20212300048592, mayo 28, 2021).

Esta discrepancia corresponde a la diferencia de criterios utilizados en el tratamiento de las iniciativas. Mientras que la Matriz IMEG-Paz utilizó la metodología indicada al principio del artículo, la ART expresa que, teniendo en cuenta la identificación hecha por las mujeres, la entidad agrupó las 4606 iniciativas de la siguiente manera:

Acciones afirmativas: dirigidas exclusivamente a las mujeres que tiene como propósito de reducir las desigualdades, sociales, culturales, económicas y políticas que han vivido históricamente las mujeres.

Acciones de transformación: Inclusión en los procesos de diseño, implementación y seguimiento de políticas, programas o proyectos, así como en los procesos de presupuestación, las necesidades e impacto entre hombres y mujeres, asegurando que mujeres y hombres se benefician de manera equitativa de los procesos del desarrollo (comunicación personal, radicado 20212300064242, julio 2, 2021).

El criterio amplio usado por la ART al momento de hacer la marcación de iniciativas mujer rural y género puede configurarse en una oportunidad, en tanto que en la implementación bajo su coordinación realmente se prioricen a las mujeres en estas iniciativas; o en una limitación, si solo se utiliza para abultar los informes de gestión en relación con el enfoque de género. Respecto a esto último, preocupa que al revisar las iniciativas 
no identificadas en la Matriz IMEG-Paz no logra establecerse cuál fue el análisis por medio del cual la ART las dispuso dentro de su clasificación como acciones afirmativas o acciones de transformación. Por ejemplo, en la subregión Alto Patía y Norte del Cauca, región que de acuerdo con la ART es la que más tiene — por mucho- iniciativas mujer rural y género (1179), en la Matriz IMEG-Paz solo se señalaron de este modo 285, una diferencia de 894 iniciativas, de las cuales una es la siguiente:

Propiciar el uso adecuado, productivo y sostenible de la tierra mediante la implementación de proceso de estudio de suelos geológicos y geomorfológicos detallados a escala 1: 25.000 y 1 : 10.000 e interpretación de resultados; para determinar la vocación del suelo, determinar las áreas de reserva y áreas productivas; este estudio ayudara a delimitar la frontera agrícola en los 13 corregimientos del municipio de Argelia Cauca.

Esta iniciativa ilustra la dificultad para establecer cuál es el enfoque de género o acción a favor de las mujeres de muchas de las medidas. Podría aducirse que cualquier medida que impacte positivamente el territorio favorecería a las mujeres, pero una perspectiva así significaría que las iniciativas no son acciones afirmativas que buscan cerrar brechas, ya que este tipo de acciones surgen, precisamente, del reconocimiento de un sistema patriarcal en el cual las mujeres suelen tener mayores dificultades para acceder a derechos y recursos de diferente índole, lo que hace necesaria una priorización para que realmente haya un beneficio equitativo por parte de hombres y mujeres de los distintos programas.

También podría darse el caso de que la ART lo que proyecte sea priorizar la participación de las mujeres en las 4606 iniciativas; no obstante, teniendo en cuenta que el proceso participativo debe continuar más allá de la construcción de los planes y que las mujeres deben ser una parte activa en todo el proceso, circunscribir el impulso de su participación a solo 4606 parece más una limitación que una oportunidad. Asimismo, varias de las iniciativas marcadas únicamente registraban lenguaje incluyente, como si esto por sí solo pudiera configurar una medida de transformación a favor de las mujeres.

En este sentido, es importante que la ART clarifique el criterio amplio utilizado en la clasificación de las iniciativas. En las distintas comunicaciones entabladas con la entidad durante la investigación, por medio de derechos 
de petición, no fue posible obtener estas claridades, pese a la buena disposición de la institución en responder con la información requerida. Por lo que puede inferirse que hay un inadecuado desarrollo metodológico en el proceso de agrupación de las iniciativas, puesto que aún si fueron las mujeres en sus territorios las que las identificaron, el acompañamiento de la ART a través de funcionarios y funcionarias capacitadas en enfoque de género era una parte fundamental de la construcción de los pactos y planes, así como lo es y será en su implementación.

En las 1814 iniciativas identificadas en la Matriz IMEG-Paz, los pilares con mayor cantidad de disposiciones fueron el 6 (reactivación económica), 7 (derecho a la alimentación), y 8 (construcción de paz) (véase gráfica 3).

Gráfica 3. Iniciativas con marcación mujer rural y género, distribuidas por pilar.

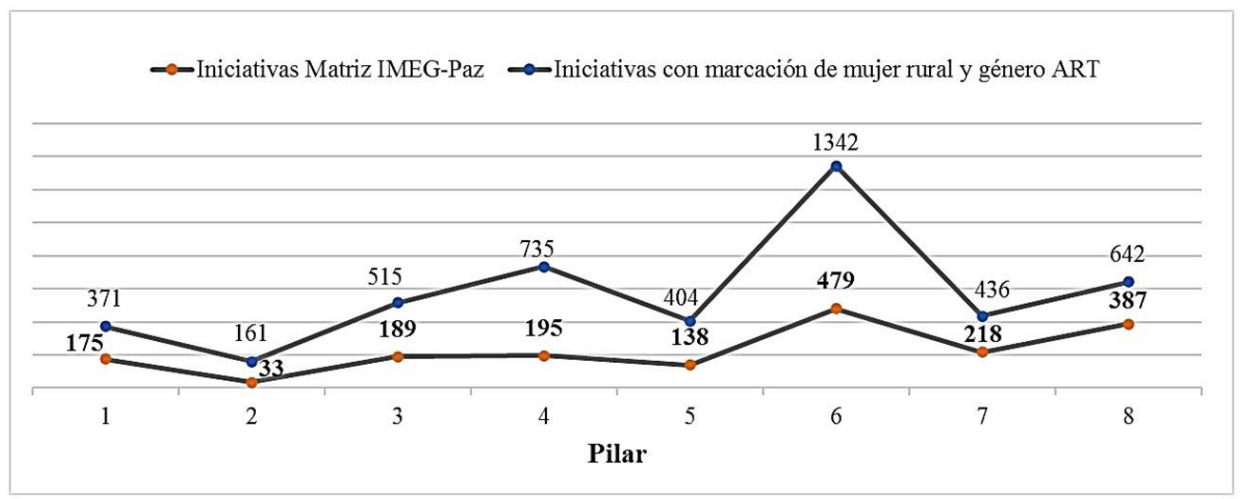

Fuente: elaboración propia a partir de la Matriz IMEG-Paz y la ART (comunicación personal, radicado 20212300048592, mayo 28, 2021).

En la parte económica las iniciativas se concentran en el fortalecimiento de las líneas productivas agropecuarias o apoyo a distintos proyectos productivos de mujeres de artesanías, modistería, ecoturismo, de conservación, agroindustriales, microempresas, entre otros, por medio de capital semilla, capacitaciones, asistencia técnica, promoción de las asociaciones y organizaciones productivas, dotación de maquinaria e insumos, robustecimiento de cadenas productivas y medios de comercialización, y demás. También se busca impulsar la vinculación laboral y afiliación a la seguridad social de las mujeres. Por parte de las iniciativas en relación con el derecho a la alimentación, estas se enfocan en la priorización de las mujeres, 
especialmente de las madres gestantes, lactantes y cabeza de familia en programas que promuevan la seguridad alimentaria, como el complemento alimentario, los restaurantes comunitarios, la educación alimentaria, la inclusión productiva y las granjas integrales y huertas caseras.

Las iniciativas en torno a la reconciliación, convivencia y construcción de paz son las más variadas, estas plantean acciones como: formulación de la política pública de la mujer; fomento de los liderazgos femeninos; capacitaciones; programas de sensibilización en género; protección a lideresas; creación de secretarías y oficinas de la mujer; promoción de la legislación y la normatividad vigente en relación con los derechos de las mujeres; impulso a mesas de población diversa y de mujeres; programas de no discriminación e inclusión de la población LGBTI; atención psicosocial y de reparación a mujeres víctimas; hogares de paso y centros de atención integral; fortalecimiento de organizaciones de mujeres afro; estudios de caracterización de la población LGBTI; promoción de prácticas que permitan transmitir los saberes ancestrales de las mujeres de los resguardos indígenas; fomento de la participación de las mujeres rurales; empoderamiento de las mujeres étnicas; entre otros. Aunque, en general, las medidas a favor de la población LGBTI son escasas, este es el

[172] pilar en el que aparecen la mayor cantidad.

En contraste con lo anterior, el pilar en el cual hay menos iniciativas con enfoque de género o para mujeres rurales, con una gran diferencia en comparación con los otros pilares, es el 8, puesto que hay pocas acciones encaminadas a vincular social y laboralmente a las mujeres en los proyectos de infraestructura.

Por otro lado, aunque el nivel de implementación de los PDET todavía es exiguo y pese a los retrasos, se ha empezado a avanzar en los proyectos y obras a través de distintas estrategias: obras PDET, Órgano Colegiado de Administración y Decisión (OCAD Paz), Proyectos Productivos, obras por impuestos, entre otros (CPEC, 2020). En este punto, es poco el seguimiento que se le puede hacer a las medidas, pero desde ya se manifiestan dos grandes obstáculos, a parte de los vinculados a la falta de claridad en la marcación realizada por la ART de las iniciativas de mujer rural y género: el primero se relaciona con la falta de precisión sobre cómo se continuará con el proceso participativo al estar ya elaborados los PDET (Cinep y Cerac, 2020b). Actualmente, se están construyendo las diferentes hojas de ruta, pero como plantea la Secretaría Técnica, todavía no hay certeza sobre «la 
estrategia de la CPEC para incluir las iniciativas con etiqueta de mujer y género en las Hojas de Ruta Únicas -HRU herramienta para articular los instrumentos de planeación» (Cinep y Cerac, 2020a, p. 16). Esta situación es la misma para el Plan Maestro de Estructuración que está desarrollando la ART para organizar los distintos proyectos PDET.

El segundo obstáculo es la dificultad para obtener la información, principalmente, porque las entidades que la generan y las organizaciones que le hacen seguimiento, cuando publican información georreferenciada territorialmente - la cual es reducida todavía-, poco tienen en cuenta a las mujeres y al enfoque de género, y viceversa; y cuando se informa sobre las medidas con enfoque de género es muy poco lo que se desagrega territorialmente. Esto, en parte, se debe a que se basan en el PMI, el cual da por cumplido el indicador sobre mujeres y PDET con la participación de estas en el proceso de formulación.

Estos problemas se suman a los contextuales: falta de voluntad política de algunos actores, incapacidades institucionales, empobrecimiento y recrudecimiento de la violencia en ciertas zonas.

\section{Planes Nacionales para la Reforma Rural Integral (PNRRI)}

Paralelamente al acceso a tierras, es necesario generar las condiciones que permitan desarrollar el campo y superar la desigualdad asociada al sector rural.

Las mujeres se enfrentan a una importante brecha de género en el acceso a los recursos productivos. Controlan menos tierras que los hombres, las que controlan suelen ser de peor calidad y carecen de seguridad sobre su tenencia. Las mujeres poseen menos animales de trabajo necesarios para la agricultura que los hombres. A menudo tampoco controlan los ingresos generados por los normalmente pequeños animales que gestionan. Las agricultoras son menos susceptibles que los hombres de utilizar insumos modernos, tales como semillas mejoradas, fertilizantes, medidas de control de plagas y herramientas mecánicas. Asimismo, utilizan menos crédito y no suelen controlarlo cuando lo obtienen.

Por último, las mujeres tienen un nivel inferior de educación y un menor acceso a los servicios de extensión, por lo que les resulta más difícil acceder a algunos de los otros recursos, como la tierra, el crédito y los fertilizantes, así como utilizarlos (FAO, 2011, p. vı). 
La situación en Colombia no dista de esa realidad, las mujeres rurales no solo tienen menor acceso a tierras y a los bienes y servicios necesarios para producirla (véase gráfica 1), sino que en general tienen menor acceso a recursos económicos (véase gráfica 4), puesto que, aunque suelen tener jornadas de trabajo más larga, realizan la mayoría de trabajos no remunerados e invisibilizados por el sistema económico, como lo son los trabajos de cuidado y la agricultura de subsistencia.

Gráfica 4. Caracterización económica de las mujeres en centros poblados y rurales dispersos.

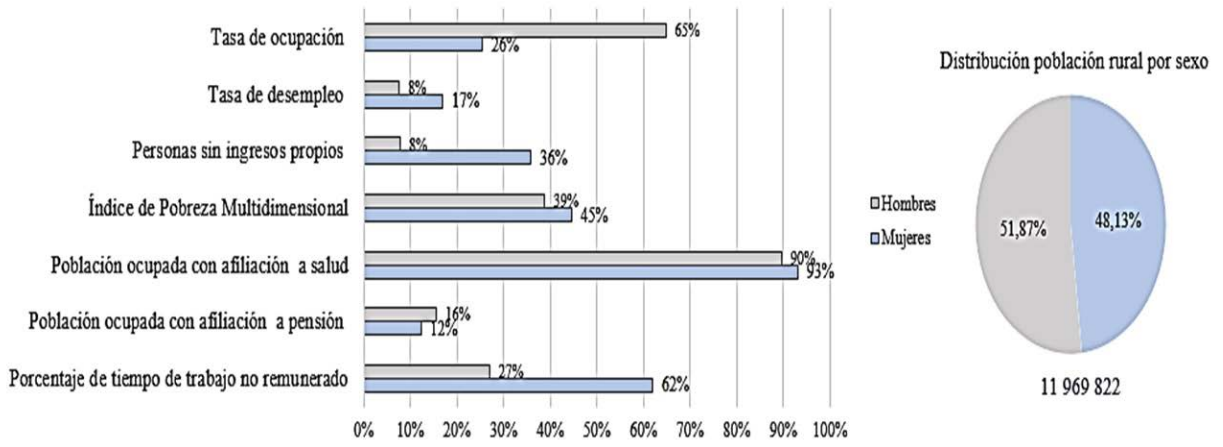

Fuente: elaboración propia a partir de CPEM (2020, noviembre 15); DANE (2020).

De los 16 planes sectoriales mencionados en el Acuerdo final que buscan, precisamente, crear las condiciones para desarrollar el campo, 14 se encuentran en el subtema PNRRI — los planes de formalización y zonificación ambiental aparecen en el subtema Tierras-. En conexión con estos planes, se identificaron 16 medidas específicas para mujeres (cuadro 3).

Cuadro 3. Medidas mujeres rurales y enfoque de género:

4. Planes Nacionales para la Reforma Rural Integral (PNRRI).

\begin{tabular}{|l|l|l|}
\hline \multicolumn{1}{|c|}{ Plan Nacional } & \multicolumn{1}{|c|}{ Resumen medida } & \multicolumn{1}{c|}{ Principales avances } \\
\hline $\begin{array}{l}\text { 16 planes } \\
\text { sectoriales }\end{array}$ & $\begin{array}{l}\text { Medidas específicas para } \\
\text { mujeres en todos los planes.* }\end{array}$ & $\begin{array}{l}\text { - A la fecha se han aprobado 9 planes, } \\
6 \text { contienen medidas específicas. }\end{array}$ \\
\hline Salud rural & $\begin{array}{l}\text { Adopción de enfoque de } \\
\text { género que considere los } \\
\text { requerimientos en salud de } \\
\text { las mujeres. }\end{array}$ & $\begin{array}{l}\text { - Plan en cierre técnico. Contiene } \\
\text { medidas específicas para mujeres y } \\
\text { población LGBTI. } \\
\text { - Modelo de Acción Integral Territorial } \\
\text { adoptado con lineamientos de género. }\end{array}$ \\
\hline
\end{tabular}


Cuadro 3. (Continuación).

\begin{tabular}{|c|c|c|}
\hline Plan Nacional & Resumen medida & Principales avances \\
\hline \multirow[t]{2}{*}{ Educación rural } & $\begin{array}{l}\text { Estrategia de formación } \\
\text { profesional en disciplinas no } \\
\text { tradicionales. }\end{array}$ & \multirow{2}{*}{$\begin{array}{l}\text { - Plan en cierre técnico. } \\
\text { - Diseño de la Estrategia de } \\
\text { Formación de Mujeres en Carreras no } \\
\text { Tradicionales por parte del Ministerio } \\
\text { de Educación Nacional (MEN). }\end{array}$} \\
\hline & $\begin{array}{l}\text { Acceso equitativo a cupos } \\
\text { nuevos en educación } \\
\text { superior e incentivos para la } \\
\text { permanencia.* }\end{array}$ & \\
\hline \multirow{3}{*}{\begin{tabular}{|l|} 
Construcción y \\
mejoramiento de \\
vivienda social rural
\end{tabular}} & $\begin{array}{l}\text { Acceso equitativo a las } \\
\text { soluciones de vivienda. }\end{array}$ & \multirow{3}{*}{$\begin{array}{l}\text { - Plan adoptado por la Resolución } 179 \\
\text { de } 2017 \text { del Ministerio de Agricultura } \\
\text { y Desarrollo Rural (MADR) con } \\
\text { medidas específicas para mujeres, } \\
\text { pero en actualización por cambio de } \\
\text { Ministerio encargado. Las viviendas } \\
\text { entregadas hasta el momento } \\
\text { corresponden a vigencias anteriores a } \\
\text { la implementación. }\end{array}$} \\
\hline & $\begin{array}{l}\text { Priorización mujer cabeza } \\
\text { de familia: subsidios para la } \\
\text { construcción de vivienda. }\end{array}$ & \\
\hline & $\begin{array}{l}\text { Priorización mujer cabeza } \\
\text { de familia: subsidios para el } \\
\text { mejoramiento de vivienda. }\end{array}$ & \\
\hline $\begin{array}{l}\text { Fomento a la } \\
\text { economía solidaria } \\
\text { y cooperativa rural }\end{array}$ & $\begin{array}{l}\text { Creación y fortalecimiento de } \\
\text { organizaciones solidarias de } \\
\text { mujeres. }\end{array}$ & $\begin{array}{l}\text { - Plan adoptado por la Resolución } \\
2951 \text { de } 2020 \text { del Ministerio del } \\
\text { Trabajo con medidas específicas. } \\
\text { - } 26 \text { organizaciones creadas }(12 \% \text { del } \\
\text { total) y } 143 \text { fortalecidas }(18 \%) . \\
\end{array}$ \\
\hline \multirow{2}{*}{$\begin{array}{l}\text { Asistencia integral } \\
\text { técnica, tecnológica } \\
\text { y de impulso a la } \\
\text { investigación }\end{array}$} & $\begin{array}{l}\text { Priorización mujeres cabeza } \\
\text { de familia: asistencia integral. }\end{array}$ & \multirow{2}{*}{$\begin{array}{l}\text { - Plan en formulación. } \\
\text { - Ley } 1876 \text { de } 2017 \text { que crea el } \\
\text { Sistema Nacional de Innovación } \\
\text { Agropecuaria, con medidas } \\
\text { específicas. } \\
\text { - } 5213 \text { mujeres atendidas ( } 33 \% \text { del } \\
\text { total) con el servicio de extensión. }\end{array}$} \\
\hline & $\begin{array}{l}\text { Participación en el sistema de } \\
\text { seguimiento y evaluación del } \\
\text { servicio de asistencia.* }\end{array}$ & \\
\hline $\begin{array}{l}\text { Apoyar y consolidar } \\
\text { la generación de } \\
\text { ingresos }\end{array}$ & $\begin{array}{l}\text { Facilitar acceso al } \\
\text { financiamiento. }\end{array}$ & $\begin{array}{l}\text { - Plan adoptado por la Resolución } \\
\text { 000209 de } 2020 \text { del MADR con } \\
\text { medidas específicas. } \\
\text { - Creación de LEC con medidas } \\
\text { especiales (Resolución } 18 \text { de } 2019 \text { de } \\
\text { la CNCA). } \\
\text { - } 422806 \text { mujeres accedieron a } \\
\text { crédito blando ( } 30 \% \text { del total). }\end{array}$ \\
\hline $\begin{array}{l}\text { Promoción de la } \\
\text { comercialización }\end{array}$ & $\begin{array}{l}\text { Promoción de asociaciones } \\
\text { solidarias de mujeres rurales } \\
\text { para comercialización. }\end{array}$ & $\begin{array}{l}\text { - Plan adoptado por la Resolución } \\
00006 \text { de } 2020 \text { del MADR con } \\
\text { medidas específicas. } \\
\text { - No se han creado o apoyado } \\
\text { organizaciones para la } \\
\text { comercialización. }\end{array}$ \\
\hline
\end{tabular}


Cuadro 3. (Continuación).

\begin{tabular}{|l|l|l|}
\hline \multicolumn{1}{|c|}{ Plan Nacional } & \multicolumn{1}{|c|}{ Resumen medida } & \multicolumn{1}{c|}{ Principales avances } \\
\hline Protección social & $\begin{array}{l}\text { Promoción de vinculación } \\
\text { laboral en áreas no } \\
\text { tradicionales. }\end{array}$ & $\begin{array}{l}\text { - Plan adoptado por la Resolución } \\
\text { 2951 de 2020 del Ministerio del } \\
\text { Trabajo con medidas específicas. }\end{array}$ \\
\cline { 2 - 2 } & $\begin{array}{l}\text { Protección a la adulta mayor } \\
\text { del riesgo económico de la } \\
\text { vejez.* }\end{array}$ & $\begin{array}{l}\text { con cobertura del Servicio Público de } \\
\text { Empleo, con énfasis en la vinculación } \\
\text { laboral en áreas no tradicionales. }\end{array}$ \\
\cline { 2 - 3 } & $\begin{array}{l}\text { Esquemas de protección al } \\
\text { embarazo, parto, lactancia y } \\
\text { atención al recién nacido. }\end{array}$ & \\
\hline $\begin{array}{l}\text { Sistema para } \\
\text { la Garantía del } \\
\text { Derecho a la } \\
\text { Alimentación }\end{array}$ & $\begin{array}{l}\text { Priorización: mujeres } \\
\text { gestantes y lactantes. }{ }^{*}\end{array}$ & $\begin{array}{l}\text { - Plan Nacional del Sistema para la } \\
\text { Alimentán Progresiva del Derecho a la }\end{array}$ \\
\hline $\begin{array}{l}\text { *Medidas sin indicador técnico. } \\
\text { Cantidad de PNRRI adoptados con fecha de corte de julio de 2021. }\end{array}$ \\
\hline
\end{tabular}

Fuente: elaboración propia a partir de CPEC (2021); Cinep y Cerac (2020b); Ministerio de Salud y Protección Social (Resolución proyecto de 2020); Instancia Especial de Mujeres para [176] el Enfoque de Género en la Paz (2019); MADR (Resolución 000006 del 15 de enero de 2020; Resolución 000209 del $1 .^{\circ}$ de septiembre de 2020); SIIPO (s. f.); Ministerio del Trabajo (s. f).

Los progresos en este subtema se vinculan más a la formulación o aprobación de los respectivos PNRRI que a su real implementación. Preocupa la dificultad ya mencionada para acceder a información clara, actualizada y desagregada. Este problema se agrava por el hecho de que las distintas entidades están generando sus informes de resultados en torno al PMI, dado que este es muy limitado en cuanto al seguimiento del enfoque de género, entre otras razones porque se olvida que el enfoque debe ser transversal a la implementación del Acuerdo final y, por lo tanto, debería haberse desagregado en la medida de lo posible la mayor parte de los indicadores. Conjuntamente, pese a que los cálculos más conservadores hablan de al menos 100 disposiciones con enfoque de género en el Acuerdo, el PMI solo establece 51 indicadores para hacer el seguimiento; además, muchos indicadores no tienen línea de base ni metas claras, o las metas son muy bajas y no se desagregan territorialmente, lo que dificulta hacer el seguimiento en los municipios PDET, y tampoco desagregan con enfoque diferencial; adicionalmente, los indicadores son de gestión o de resultados, 
y no de impacto (Instancia Especial de Mujeres para el Enfoque de Género en la Paz, 2019).

\section{Consideraciones finales}

A lo largo del artículo se intentó exponer el estado de implementación de las medidas con enfoque de género en la RRI. Aun entendiendo que esta, como la paz, es un proceso a largo plazo, los avances no dejan de ser mínimos. A cuatro años del Acuerdo final, es momento de que la implementación a corto plazo de planeación y adecuación institucional y normativa le dé paso a la materialización de las medidas. Por supuesto, todavía queda tiempo por delante y no se puede desconocer lo avanzado, pero es necesario acelerar la implementación para que las iniciativas con enfoque de género se concreten más allá del papel y los planes.

Uno de los subtemas que genera más preocupación es el de tierras, no solo por su baja implementación, sino porque de este dependen otras medidas como la asistencia técnica, subsidios o créditos. El acceso a tierras se vincula al reconocimiento de las mujeres rurales, y es una precondición para la superación de las inequidades a las que están expuestas. Es fundamental acelerar este punto, el cual puede ser uno de los más transformativos del Acuerdo final, de la mano de las demás medidas contenidas en los PNRRI y los PDET que son complementarias al subtema de tierras, en el propósito superior de mejorar la vida de las mujeres al encaminarse a proveer los bienes y servicios necesarios para alcanzar este objetivo.

Asimismo, es preocupante la dificultad para acceder a información clara, actualizada y desagregada de distintas medidas, lo cual es necesario para hacer seguimiento, monitoreo y control ciudadano al Acuerdo final. Esto es especialmente perceptible en las iniciativas PDET, debido a la falta de información desagregada territorialmente entrecruzada con el enfoque de género. Con base en lo anterior, es transcendental que las instituciones públicas y privadas que hacen seguimiento a los avances del Acuerdo generen más información sobre cómo se está construyendo la paz territorialmente y no solo desde el centro. Los últimos informes de la CPEC y la ART han dado pasos en este sentido, pero, desde luego, los informes de las entidades, aunque valiosos, en muchos casos son una compilación de logros. Por eso es importante lo que empieza a realizar la Secretaría Técnica de focalizar los PDET Sur de Córdoba, Pacífico Medio y Catatumbo, en un primer ejercicio de análisis de la implementación territorial. Es fundamental 
que las demás organizaciones sociales y académicas, como el Instituto Kroc, también comiencen a georreferenciar más la información que publican. Asimismo, es elemental que además de territorializar la mirada se le cruce con el enfoque de género, estas no pueden ser acciones que van por caminos separados. Focalizar, implementar, fortalecer y monitorear la construcción de paz territorial desde y para las mujeres debe ser una prioridad, puesto que no hay transformación posible del campo si no se transforma la vida de las mujeres rurales.

\section{Referencias bibliográficas}

1. Bartra, Eli. (2010). Acerca de la investigación y la metodología feminista. En: Blazquez Graf, Norma; Flores Palacios, Fátima y Ríos Everardo, Maribel (coords.). Investigación feminista: epistemología, metodología y representaciones sociales (pp. 67-77). México, D. F.: UNAM. http://biblioteca.clacso.edu.ar/Mexico/ceiichunam/20170428032751/pdf_1307.pdf

2. Centro de Investigación y Educación Popular (Cinep) y Centro de Recursos para el Análisis de Conflictos (Cerac). (2018). Segundo informe de verificación de la implementación del Enfoque de Género en el Acuerdo Final de Paz en Colombia para los Verificadores Internacionales Felipe Conzález y José Mujica (A.F. 6.3.2). Bogotá, D. C.: Cinep-Cerac. https://www.verificacion.cerac.org.co/wp-content/ uploads/2018/12/Segundo-Informe-de-Implementaci\%C3\%B3n-del-Enfoque-deG\%C3\%A9nero-STCVI.pdf

3. Centro de Investigación y Educación Popular (Cinep) y Centro de Recursos para el Análisis de Conflictos (Cerac). (2020a). Cuarto informe de verificación de la implementación del enfoque de género en el Acuerdo Final de Paz en Colombia. Bogotá, D. C.: Cinep-Cerac. https://www.verificacion.cerac.org.co/wp-content/ uploads/2020/10/Cuarto-Informe-de-Genero.pdf

4. Centro de Investigación y Educación Popular (Cinep) y Centro de Recursos para el Análisis de Conflictos (Cerac). (2020b). Séptimo informe de verificación de la implementación del Acuerdo Final de Paz. Bogotá, D. C.: Cinep-Cerac. https:// www.verificacion.cerac.org.co/wp-content/uploads/2020/09/Septimo-Informe-deVerificacion-STCVI-22-Sept-2020.pdf

5. Centro Nacional de Memoria Histórica (CNMH). (2014). Guerrilla y población civil. Trayectoria de las FARC 1949-2013. Bogotá, D. C.: CNMH. http://www. centrodememoriahistorica.gov.co/descargas/informes2013/farc/guerrilla-poblacioncivil.pdf

6. Colombia. Comisión Nacional de Crédito Agropecuario (CNCA). Resolución 4 (8 de mayo de 2019). «Por la cual se establece una Línea Especial de Crédito para la Compra de Tierras para Uso Agropecuario y se dictan otras disposiciones». 
https:/www.finagro.com.co/sites/default/files/field-collection/tabla-resoluciones/files/ resolucion_no_4_mayo_08_de_2019.pdf

7. Colombia. Corte Constitucional. Auto 092. (14 de abril de 2008). https://www. corteconstitucional.gov.co/relatoria/autos/2008/a092-08.htm

8. Colombia. Ministerio de Agricultura y Desarrollo Rural (MADR). Resolución 000006. (15 de enero de 2020). «Por la cual se adopta el Plan Nacional para la Promoción de la Comercialización de la Producción de la Economía Campesina, Familiar y Comunitaria, formulado en cumplimiento de lo establecido en el Punto 1.3.3.4 del Acuerdo Final». https://www.minagricultura.gov.co/Normatividad/ Resoluciones/RESOLUCI\%C3\%93N\%20NO.\%20000006\%20DE\%202020.pdf

9. Colombia. Ministerio de Agricultura y Desarrollo Rural [MADR]. Resolución 000209 (1. ${ }^{\circ}$ de septiembre de 2020). «Por la cual se adopta el Plan Nacional para apoyar y consolidar la Generación de Ingresos de la Economía Campesina, Familiar y Comunitaria, formulado en cumplimiento de lo establecido en el Punto 1.3.3.3 del Acuerdo Final de Paz». https://www.minagricultura.gov.co/Normatividad/ Resoluciones/RESOLUCI\%C3\%93N\%20NO.\%20000209\%20DE\%202020.pdf

10. Colombia. Ministerio de Justicia y del Derecho. Proyecto de Ley 134. (20 de julio de 2020). «Por la cual se crea una especialidad judicial rural y agraria, se establecen los mecanismos para la resolución de controversias y litigios agrarios y rurales y se dictan otras disposiciones». https://www.camara.gov.co/especialidadjudicial-rural-y-agraria

11. Colombia. Ministerio de Salud y Protección Social. Resolución proyecto (2020). Por la cual se adopta el Plan Nacional de Salud Rural-PNSR y se establece la ruta metodológica para su implementación. https://www.normassalud.com/archivos/ 133806ca086fa756e78e210c0aca10be245bd2f8ad9544cb599e355020bbd59b

12. Colombia. Presidencia de la República. Decreto 2367. (7 de diciembre de 2015). «Por el cual se crea el Consejo Superior de la Administración de Ordenamiento del Suelo Rural». http://wp.presidencia.gov.co/sitios/normativa/decretos/2015/ Decretos 2015/DECRETO \% 202367\% 20DEL \% 207\% 20DE \% 20DICIEMBRE \% 20 DE\%202015.pdf

13. Colombia. Presidencia de la República. Decreto Ley 893. (28 de mayo de 2017). «Por el cual se crean los Programas de Desarrollo con Enfoque Territorial -PDET». http://es.presidencia.gov.co/normativa/normativa/DECRETO $\% 20893 \% 20$ DEL\%2028\%20DE\%20MAYO\%20DE\%202017.pdf

14. Colombia. Presidencia de la República. Decreto Ley 902 (29 de mayo de 2017). «Por el cual se adoptan medidas para facilitar la implementación de la Reforma Rural Integral contemplada en el Acuerdo Final en materia de tierras, específicamente el procedimiento para el acceso y formalización y el Fondo de Tierras». http:// es.presidencia.gov.co/normativa/normativa/DECRETO \%20902\%20DEL \% 2029\%20 DE\%20MAYO\%20DE\%202017.pdf 
15. Consejería Presidencial para la Equidad de la Mujer (CPEM). (2020, noviembre 15). Información Día de la Mujer Rural. Observatorio Colombiano de las Mujeres. https://observatoriomujeres.gov.co/archivos/publicaciones/Publicacion_67.pdf

16. Consejería Presidencial para la Estabilización y la Consolidación (CPEC). (2021). Informe de gestión. Paz con Legalidad. Agosto 2018-abril 2021. 32 meses. Portal para la Paz. https://www.portalparalapaz.gov.co/loader.php?lServicio = Tools2 $\& \mathrm{ITipo}=$ descargas \&IFuncion $=$ descargar \&idFile $=682$

17. Consejería Presidencial para la Estabilización y la Consolidación (CPEC). (2020). Informe de gestión. Agosto 7, 2018-septiembre 30, 2020. 25 meses. Portal para la Paz. http://www.portalparalapaz.gov.co/loader.php?IServicio=Tools2\&ITipo $=$ descargas \&IFuncion $=$ descargar\&idFile $=382$

18. Departamento Administrativo Nacional de Estadística (DANE). (2016). 3. ${ }^{\text {er }}$ Censo Nacional Agropecuario. Hay campo para todos. Tomo 2. Resultados. Bogotá D. C.: DANE. https://www.dane.gov.co/files/images/foros/foro-de-entrega-de-resultadosy-cierre-3-censo-nacional-agropecuario/CNATomo2-Resultados.pdf

19. Departamento Administrativo Nacional de Estadística (DANE). (2020). Mujeres rurales en Colombia. Bogotá D. C.: DANE. https:/www.dane.gov.co/files/ investigaciones/notas-estadisticas/sep-2020-\%20mujeres-rurales.pdf

20. Departamento Nacional de Planeación (DNP). (s. f.). Plan Marco de Implementación. Acuerdo final para la terminación del conflicto y la construcción de una paz estable y duradera. https:/colaboracion.dnp.gov.co/

[180] CDT/Conpes/Econ\%C3\%B3micos/3932_Anexo\%20B_Plan\%20Marco\%20de\%20 Implementaci\%C3\%B3n\%20(PMI).pdf

21. Ferrajoli, Luigi. (2019). Igualdad, desarrollo económico y democracia. Isonomía, 49, pp. 173-186. https://doi.org/10.5347/49.2018.28

22. Fondo de Población de las Naciones Unidas (UNFPA) y ONU-Hábitat. (s. f.). Mujeres y Tierra. Recuperación temprana y género en la Ley de víctimas y tierras en Colombia. UNFPA. https://colombia.unfpa.org/sites/default/files/pub-pdf/Mujeresy-Tierradigital_0.pdf

23. Gobierno de Colombia y FARC-EP. (2016). Acuerdo final para la terminación del conflicto y la construcción de una paz estable y duradera. Portal para la Paz. http:// www.portalparalapaz.gov.co/publicaciones/809/texto-del-acuerdo/

24. Grupo de Memoria Histórica (GMH). (2010). La tierra en disputa. Memorias de despojo y resistencia campesina en la costa Caribe (1960-2010). Bogotá, D. C.: GMH. http://www.centrodememoriahistorica.gov.co/descargas/informes2010/tierra conflicto/la_tierra_en_\%20disputa.pdf

25. Grupo Género en la Paz (GPAZ). (2019). La paz avanza con las mujeres. Observaciones sobre la incorporación del enfoque de género en el Acuerdo de Paz. http://generoypaz.co/informes/gpaz_informe_2019.pdf?

26. Humanas Colombia, Sisma Mujer, Red Nacional de Mujeres. (2017). Equidad de género y derechos de las mujeres en el acuerdo final de paz. Bogotá, 
D. C.: Humanas Colombia. https://humanas.org.co/wp-content/uploads/2020/10/09.Equidad-Genero-Mujeres-Acuerdo-final-1-1.pdf

27. Instancia Especial de Mujeres para el Enfoque de Género en la Paz. (2019). Enfoque de género y paz territorial. "Balance a tres años de la firma del Acuerdo de Paz». Bogotá, D. C.: Instancia Género. https://www.instanciagenero.org/wp-content/ uploads/2019/12/Informe-final-Instancia-Especial-de-Mujeres-para-el-Enfoque-deG\%C3\%A9nero-en-la-Paz.pdf

28. Instituto Kroc de Estudios Internacionales de Paz. (2020). Tres años después de la firma del Acuerdo Final de Colombia: hacia la transformación territorial. Informe 4. Bogotá, D. C.: Universidad de Notre Dame. http://peaceaccords.nd.edu/wp-content/ uploads/2020/09/091620-Reporte-4-Digital-.pdf

29. Lagarde, Marcela. (1994). Perspectiva de género. Diakonia, 71, pp. 23-29.

30. Lederach, John Paul. (2007). Construyendo la paz. Reconciliación sostenible en sociedades divididas. Bogotá, D. C.: UNDP; Justapaz; Catholic Relief Services.

31. Meertens, Donny. (2016a). Entre el despojo y la restitución: reflexiones sobre género, justicia y retorno en la costa caribe colombiana. Revista Colombiana de Antropología, 52 (2), pp. 45-71. https://doi.org/10.22380/2539472X39

32. Meertens, Donny. (2016b). Restitución de tierras, justicia de género y paz. Versión revisada y ampliada. Bogotá, D. C.: Pontificia Universidad Javeriana. https:// issuu.com/pujaveriana/docs/restituci_n_de_tierras_taco_portada

33. Ministerio del Trabajo. (s. f). Plan Progresivo de Protección Social y de Garantía de Derechos de los Trabajadores y Trabajadoras Rurales. https://www.mintrabajo.gov. co/documents/20147/0/Plan + Progresivo + adopci\%C3\%B3n.pdf/d8a259be-7d13cd85-bb7a-0082f6548690?t = 1598984128245

34. Naciones Unidas. Consejo de Seguridad. Resolución 1325. (31 de octubre de 2000). https://undocs.org/es/S/RES/1325\%20\%282000\%29

35. Observatorio de Tierras Rurales (OTR). (s. f.). Acceso a tierras y adjudicación de baldíos. http://otr.agenciadetierras.gov.co/OTR/Observatorio/AccesoATierras

36. ONU Mujeres. (2018). 100 medidas que incorporan la perspectiva de género en el Acuerdo de Paz entre el Gobierno de Colombia y las FARC-EP para terminar el conflicto y construir una paz estable y duradera. Bogotá, D. C.: ONU Mujeres Colombia. https://www2.unwomen.org/-/media/field\%20office\%20colombia/ documentos/publicaciones/2017/10/internas\%20farc-ep.pdf?la = es\&vs = 4845

37. Organización de las Naciones Unidas para la Agricultura y la Alimentación (FAO). (2011). El estado mundial de la agricultura y la alimentación. Las mujeres en la agricultura. Cerrar la brecha de género en aras del desarrollo. Roma: FAO. http:// www.fao.org/3/i2050s/i2050s.pdf

38. Ortega López, Teresa. (2015). Jornaleras, campesinas y agricultoras: La historia agraria desde una perspectiva de género. Zaragoza: Prensas Universitarias de Zaragoza. 
39. Pérez Portilla, Karla. (2010). Más allá de la igualdad formal: dignidad humana y combate a la desventaja. En: Carpizo, Jorge y Arriaga, Carol B. (coords.). Homenaje al Doctor Emilio O. Rabasa (pp. 655-674). México, D. F.: UNAM.

40. Rettberg, Angelika. (2013). La construcción de paz bajo la lupa: una revisión de la actividad y de la literatura académica internacional. Estudios Políticos, 42, pp. 13-36. https://revistas.udea.edu.co/index.php/estudiospoliticos/article/view/15782

41. Segato, Rita. (2018). Contra-pedagogías de la crueldad. Buenos Aires: Prometeo.

42. Sistema Integrado de Información para el Posconflicto (SIIPO). (s. f.). A.351 Porcentaje de territorios definidos en el respectivo plan con cobertura del Servicio Público de Empleo en zonas rurales con énfasis en la vinculación laboral de las mujeres en áreas productivas no tradicionales. SIIPO. https://siipo.dnp.gov.co/ detalleindicador/QhXAbcYqaq48Plylv69i

43. UN Women. (s. f.). Fourth World Conference on Women. https://www. un.org/womenwatch/daw/beijing/fwcwn.html

44. Valencia Agudelo, Germán Darío. (2017). Organizarse para negociar la paz. Un análisis político transaccional de las estructuras de gobernanza de las de la paz negociada en Colombia, 1981-2016. (Tesis inédita de doctorado). Universidad Externado de Colombia, Bogotá, D. C. 